\title{
Ensaio sobre metodologias ativas: reflexões e propostas
}

\author{
Essay on active learning methodologies: thoughts and proposals
}

\author{
Ana Rita Mota* \\ Cleci T. Werner da Rosa
}

\section{Resumo}

As metodologias ativas surgiram na década de 1980 como alternativa a uma tradição de aprendizagem passiva, onde a apresentação oral dos conteúdos, por parte do professor, se constituía como única estratégia didática. Contrariamente ao ensino tradicional, as metodologias ativas procuram um ambiente de aprendizagem onde o aluno é estimulado a assumir uma postura ativa e responsável em seu processo de aprender, buscando a autonomia, a autorregulação e a aprendizagem significativa. Estas metodologias envolvem métodos e técnicas que estimulam a interação aluno-professor, aluno-aluno e aluno-materiais/recursos didáticos e apostam, quase sempre, na aprendizagem em ambiente colaborativo, levando o aluno a responsabilizar-se pela construção do seu conhecimento. Tendo como pano de fundo a psicologia cognitiva e a metacognição, este artigo apresenta, analisa e explora algumas metodologias ativas de ensino. Paralelamente, são fornecidas recomendações práticas para envolver o aluno ativamente em sala de aula, assim como são referidas as potencialidades do uso combinado das diferentes metodologias ativas.

Palavras-chave: Metodologias ativas. Ensino colaborativo. Metacognição. Peer Instruction. Team-based learning.

\section{Abstract}

The active learning methodologies emerged in the 1980 s as an alternative to a passive learning tradition, where the oral presentation of the contents by the teacher was constituted as the only didactic strategy. Contrary to traditional teaching, active methodologies seek a learning environment where the student is encouraged to take an active and responsible ownership of their learning, seeking autonomy, self-regulation and meaningful learning. These methodologies involve methods and techniques that encourage student-teacher interaction, student-student and student-materials / didactic resources and bet, almost always, on learning in a collaborative environment, leading the student to take responsibility for building their knowledge. Based on cognitive psychology and metacognition, this article presents, analyzes and explores some active teaching methodologies. Pedagogical recommendations are provided to involve the student actively in the classroom, as well as the potentialities of the combined use of different active methodologies.

Keywords: Active teaching-learning methodologies. Collaborative learning. Metacognition. Peer instruction. Team-based learning.

Recebido em 27/09/2017 - Aprovado em 16/01/2018

http://dx.doi.org/10.5335/rep.v25i2.8161

Doutora em Física pela Universidade do Porto, Portugal, com Estágio pós-doutoral na Universidade de Harvard, EUA. Pesquisadora no Centro de Física do Porto, Departamento de Física e Astronomia, Universidade do Porto, Portugal. E-mail: ana.mota@fc.up.pt

** Doutora em Educação Científica e Tecnológica pela Universidade Federal de Santa Catarina. Docente no Programa de Pós-Graduação em Educação e no Programa de Pós-Graduação em Ensino de Ciências e Matemática. Professora de Física na Universidade de Passo Fundo, Brasil. 


\section{Professor, por favor, não use lâminas!}

O mundo acadêmico, a par da comunidade docente, tem procurado desenvolver, implementar e avaliar ambientes educativos que permitam o desenvolvimento de competências essenciais como a autonomia intelectual, o pensamento crítico e a capacidade de aprender a aprender. Esta procura justifica-se pela vasta investigação na área da educação em ciências que mostra evidências claras que ambientes de ensino passivos, focados na exposição verbal docente são ineficazes, quer para a aprendizagem de conceitos concretos, quer para o desenvolvimento de competências essenciais para a vida futura (DESLAURIERS; SCHELEW; WIEMAN, 2011; FORMICA; EASLEY; SPRAKER, 2010; HAKE, 1998; MAZUR; HILBORN, 1997; MCDERMOTT, 1996; THACKER; KIM; TREFZ, 1994). Esta ineficácia é consequência da complexidade de processos orgânicos (nomeadamente cognitivos) mas também e sobretudo da dificuldade dos alunos se manterem mentalmente ativos na sala de aula. Ainda que as aulas sejam suficientemente interessantes com demonstrações extraordinárias e explicações verbais simples e muito bem elaboradas, isso não leva por si só à compreensão e assimilação dos processos (ARONS, 1997).

A aprendizagem significativa só é possível quando o aluno constrói o seu próprio conhecimento e para tal precisa estar mentalmente ativo. Quando os alunos estudam apenas para os momentos de avaliação, a aprendizagem corre o risco de ficar reduzida à memorização.

Ensinar Ciências, nomeadamente Física, traz consigo outra dificuldade: a interferência de ideias equivocadas, normalmente trazidas pela experiência do dia a dia; as chamadas concepções alternativas (VOSNIADOU, 2002; CHI; ROSCOE, 2002). A aprendizagem não é apenas a aquisição de novo conhecimento, é apesar de tudo interação entre o novo conhecimento com o que já existia, o que torna a aprendizagem conceptual de alguns tópicos de Física muito delicada, especialmente quando os estudantes trazem para a sala de aula concepções erradas. Nessas situações torna-se imprescindível promover a mudança conceptual, impossível de alcançar com abordagens tradicionais, baseadas em exposições verbais por parte do professor. Por esse motivo, é importante que os professores conheçam estas concepções antes de prepararem cada tópico que vão lecionar e ajudarem os alunos a ter consciência das limitações dessas concepções.

Esta consciencialização de ideias erradas só é possível com um ensino ativo, que envolvam estratégias onde o aluno possa fazer observações que entrem em conflito com as suas previsões. Dissonância cognitiva e surpresa são duas ferramentas pedagógicas que ajudam os alunos a tomarem consciência das inconsistências e limitações da sua forma de pensar. Neste contexto, os ambientes interativos, bem 
pensados e planeados, têm um papel crucial porque se constituem como ambientes privilegiados de conflito conceptual (MILLER et al., 2013).

As metodologias ativas, com início na década de 1980, procuraram dar resposta à multiplicidade de fatores que interferem no processo de aprendizagem e à necessidade dos alunos desenvolverem habilidades diversificadas. Era necessário que o aluno adquirisse um papel mais ativo e proativo, comunicativo e investigador. De certa maneira, essas metodologias opõem-se a métodos e técnicas que enfatizam a transmissão do conhecimento. Elas defendem uma maior apropriação e divisão das responsabilidades no processo de ensino-aprendizagem, no relacionamento interpessoal e no desenvolvimento de capacidade para a autoaprendizagem. O papel do professor foi também repensado; passou de transmissor do conhecimento para monitor, com o dever de criar ambientes de aprendizagem repleto de atividades diversificadas.

\section{Psicologia cognitiva e metacognição: a viagem entre ensinar e aprender}

A pesquisa no ensino da Física começou a surgir, timidamente, nos anos de 1970-1980. As décadas iniciais foram marcadas por uma forte ênfase na produção de materiais. Um pouco pelos novos projetos curriculares que surgiram nos anos que sucederam a Guerra Fria, como o curso de Física do PSSC (Physical Sciene Study Commitee). Estes projetos eram baseados na construção de materiais apoiados na pouca investigação existente, caracterizada em grande parte, pelo movimento da concepções alternativas e nos estudos sobre mudança conceptual (VIENNOT, 2003; MCDERMOTT; SHAFFER, 2001).

Áreas como "Resolução de Problemas" e "Representações mentais dos alunos," surgem depois, após a desilusão sentida pela falta de ineficácia destes novos projetos que apesar da sua contribuição positiva não tiveram o impacto esperado (MCDERMOTT, 1993). Acerca destes projetos, que pecaram pela falta de conhecimento sobre como decorria a aprendizagem do aluno, Moreira refere:

[...] os projetos foram muito claros em dizer como se deveria ensinar a Física (experimentos, demonstrações, projetos, "hands on", história da Física), mas pouco ou nada disseram sobre como aprender-se-ia esta mesma Física. Ensino e aprendizagem são interdependentes; por melhor que sejam os materiais instrucionais, do ponto de vista de quem os elabora, a aprendizagem não é uma consequência natural (2000, p. 95).

A Psicologia cognitiva, focada no estudo dos processos mentais relacionados com a aprendizagem, veio dar um importante contributo ao conhecimento de processos de aprendizagem, memorização, análise crítica, compreensão e atenção. A investigação em compreensão conceptual e resolução de problemas estava muito 
focada em investigar as dificuldades em aprender Física e para isso desenvolveram estratégias e currículos para combaterem exclusivamente essas mesmas dificuldades. Compreender como os alunos aprendem veio trazer um novo fôlego, para compreender que a produção massiva de materiais era insuficiente para melhorar o processo de aprendizagem.

Paralelamente, nos últimos 30 anos, produziram-se grandes avanços no domínio das neurociências. Aprender é mudar o cérebro, aumenta a sobrevivência e a complexidade dos novos neurônios. A compreensão dos mecanismos biológicos subjacentes à aprendizagem veio ajudar a desenhar novas e mais eficientes estratégias para promover a aquisição de conhecimentos e competências. Esta área mostrou que o cérebro precisa de tempo para assimilar, que a emoção tem implicações na aprendizagem e salientou a importância de aprender em um contexto, utilizando ao máximo as situações vivenciadas no cotidiano (NATIONAL RESEARCH COUNCIL, 2000).

De certa forma, as metodologias ativas apresentam-se vinculadas a psicologia cognitiva, de modo especial ao socioconstrutivismo e a metacognição. A metacognição, enquanto estratégia de aprendizagem, tem vindo a ocupar um lugar privilegiado na esfera educativa ao salientar a importância da reflexão e da autonomia do aluno no processo de aprendizagem. As raízes históricas da metacognição remontam ao psicólogo John Flavell $(1976,1979)$ e reside na capacidade de cada sujeito de se conhecer a si próprio e controlar, regular e avaliar os seus mecanismos de aprendizagem. Na esfera educativa, a metacognição emerge como estratégia de aprendizagem, uma vez que é importante que o estudante se conheça a si próprio e aprenda a regular e a monitorar a busca pelo conhecimento, procurando ser autônomo e gestor da sua aprendizagem. A metacognição engloba duas componentes: o conhecimento do próprio conhecimento e o controle e regulação dos processos executivos (FLAVELL, 1979).

Particularmente com relação às estratégias metacognitivas, Paris, Wasik e Turner (1991) salientam que referem-se a procedimentos que os alunos utilizam para planejar, monitorar e avaliar a sua aprendizagem, tomando assim consciência dos mecanismos favorecedores da sua aprendizagem. Este processo exige reflexão, autonomia, motivação, paciência para aprender e confiança em si mesmo e nos outros, com os quais serão compartilhadas as situações de aprendizagem. O professor é visto como um mediador do conhecimento que cria e desenvolve ambiente de aprendizagem e compartilha com os estudantes a responsabilidade do ato de ensinar e aprender. A identificação do que o estudante já conhece e o sentimento que ele tem em relação a si próprio são mecanismos essenciais, pois mobilizam toda a estrutura de pensamento. Por exemplo, a identificação de que tem dificuldades 
num determinado assunto pode levá-lo a prestar mais atenção nas explicações do professor, ou a desistir mais facilmente da sua compreensão.

Fundamentada na psicologia cognitiva, mais propriamente na perspetiva construtivista, a metacognição emerge com estratégia capaz de responsabilizar o estudante pela análise, regulação e avaliação dos mecanismos promotores da sua aprendizagem. São vários os estudos que comprovam que os estudantes que têm um papel ativo no exercício de pensar sobre o seu próprio pensamento e analisar o que estão a fazer são mais capazes de compreender a informação e ter melhores resultados acadêmicos (GEORGHIADES, 2004; PINTRICH, 2002). É importante que o aluno se pergunte frequentemente a si próprio: "Será que estou compreendendo ou apenas memorizando?"

Alguns autores apontam estratégias metacognitivas em sala de aula e instrumentos que podem apoiar o planejamento didático-pedagógico, sua estruturação, organização, definição de objetivos instrucionais e escolha de instrumentos de avaliação (ROSA, 2014; FISHER, 1998). Uma das sugestões é apostar no trabalho de equipe. Os estudantes, ao discutirem com seus pares ativam sua estrutura cognitiva e podem tomar consciência sobre o que estão fazendo. Inconscientemente e insistentemente, procuram o conhecimento já existente na estrutura cognitiva. Esta procura estimula a criação de novos conhecimentos e contribui para o controle dos seus processos mentais e, consequentemente, para a melhoria da estrutura cognitiva.

Cabe ao professor ajudar o aluno a sentir-se confortável com os seus próprios erros. Os alunos devem reconhecer que podem ser bem sucedidos se aprenderem as estratégias adequadas. O seu nível de confiança pode aumentar se o professor introduzir a importância de desenvolver competências metacognitivas e a diferença entre ler e aprender o que leu. Por outro lado, é importante que os alunos resolvam problemas distintos dos que deram origem ao conhecimento. Isso ajuda-os a pensarem de forma criativa e crítica. Ou ainda, é importante mostrar para os alunos a importância em destinar um tempo significativo para identificar os problemas com outros já resolvidos (identificar a tarefa e estratégia utilizada), bem como em tentar planificar a ação a ser executada para resolver o problema proposto. Além disso, torna-se fundamental comparar a sua resolução com as soluções ja apresentadas, avalaindo-as e refletindo os resultados e caminhos percorridos.

Por outro lado, estratégias que desenvolvam o sentido de responsabilidade, como avaliar os trabalhos dos colegas, encorajá-los a preparar pequenos momentos de aula, ensiná-los a tirar notas e criar ambientes onde o aluno tenha tempo para refletir sobre o que é ensinado, são muito bem-vindos no desenvolvimento de competências metacognitivas. Ajudam o aluno a pensar sobre a sua própria maneira de pensar. 


\section{Dez estratégias para promover metodologias ativas}

Apesar de existir um corpo sólido em termos de metodologias ativas (DOCKTOR; MESTRE, 2014) identificam-se nas investigação da área, várias estratégias que são improtantes quando se busca impleemntar tais metodologias. A seguir, apresenta-se algumas delas:

a) Nunca fale mais do que 10 min seguidos! O tempo de aula deve ser utilizado preferencialmente para discutir ideais, não para apresentar conteúdos aos alunos (KNIGHT, 2004). Por outro lado, estudos internacionais apontam que os alunos só retêm significativamente $70 \%$ dos conteúdos nos primeiros 10 min de aula. Aproveite-os!

b) Construa as suas aulas com base naquilo que o aluno já sabe. Tenha em atenção as concepções alternativas já identificadas na literatura. Dificilmente vai haver aprendizagem se a informação nova não estiver contextualizada e conectada a conhecimentos que já existem no cérebro do aluno. Recorde a Teoria da Aprendizagem Significativa de Ausubel.

c) Implemente estratégias metacognitivas em todas as aulas. $\mathrm{O}$ importante é que o aluno esteja constantemente refletindo sobre o seu próprio conhecimentos.

d) Promova o ensino colaborativo. As interações sociais e cognitivas que se processam quando os alunos trabalham com os seus pares têm um papel fundamental na aprendizagem (SLAVIN, 1984). Esta abordagem, visivelmente fundamentada na teoria social construtivista, é um dos marcos importantes das metodologias ativas. $\mathrm{O}$ ensino colaborativo favorece as atitudes de escuta, a capacidade de expressão, a troca de ideias, a negociação, o respeito e a tolerância, permitindo um processo de construção pessoal do conhecimento modelado por fatores cognitivos e não-cognitivos.

e) A melhor estratégia é mudar sempre de estratégia! Vários estudos revelam que a aprendizagem significativa é mais efetiva quando inclui sistematicamente e alternadamente diferentes ambientes. Mesmo quando os estudantes estão mentalmente ativos, o professor não pode esperar que todos os alunos estejam preparados para aprender após a primeira explicação. Ele deve voltar assim que possível ao conceito em diferentes contextos e progredir lentamente para a aplicação desses contextos para contextos cada vez mais complexos. Aparentemente, é necessário tempo para os alunos assimilarem ideias mais ou menos abstratas e se o contexto nunca for alterado, a maioria dos estudantes vai acabar apenas por memorizá-los (ARONS, 
1997). As competências de pensamento crítico, autonomia intelectual demoram tempo para serem desenvolvidas, sendo, pois, necessário desenvolver atividades para isso.

f) Avaliação constante e feedback rápido. Os melhores ambientes de aprendizagem são centrados na avaliação (NATIONAL RESEARCH COUNCIL, 2000) e a avaliação formativa é particularmente valiosa para os alunos porque oferece oportunidades para os alunos ajustarem ou esclarecer seus pensamentos antes de uma avaliação sumativa (como um exame graduado). Nas últimas décadas, a avaliação tornou-se um dos tópicos de discussão mais badalados: Assessment of learning ou Assessment for learning? A avaliação passou a ser uma estratégia de aprendizagem quando se percebeu que a aprendizagem era condicionada fortemente pela maneira como os alunos são avaliados. Nos trabalhos de casa e exames é importante elaborar questões que envolvam análise quantitativa mas também questões conceptuais e avalie de diferentes formas.

g) Motive! A motivação dos alunos condiciona a forma como os alunos aprendem. A motivação intrínseca e extrínseca desempenha papel importante na aprendizagem dos seus alunos.

h) A resolução de exercícios deve ser gradual, por grau crescente de exigência. Na preparação dos exercícios para os alunos resolverem é crucial que estes estejam por ordem crescente de complexidade (mais fácil aos mais dificeis) e por grau de abertura (mais fechados aos mais abertos). Uma descoordenação nesta organização privilegia a memorização.

i) Nunca subestime uma tarefa ou um exercício. Alguns exercícios ou tarefas práticas propostas pelos professores são muitas vezes subestimados por eles em relação a capacidade de seus alunos e acaba sendo resolvido por ele. Contudo, são essas questões que muitas vezes expõem as dúvidas e erros de pensamento dos alunos. Por esse motivo, deixe que o aluno faça todas as tarefas, mesmo que lhe pareça demasiadamente simples.

j) Avaliação de pares. Faça com que os alunos avaliem o trabalho uns dos outros. A avaliação do trabalho pelos pares pode ser feito pedindo aos alunos para resolverem um exercício individualmente no caderno. No final, os alunos trocam os cadernos de forma a corrigirem os exercícios uns dos outros. 


\section{Metodologias ativas: alguns exemplos no cenário educativo mundial}

Ao longo das últimas décadas vários programas de metodologias ativas foram desenvolvidos e testados (DOCKTOR; MESTRE, 2014). Elas apresentam em comum o objetivo de trazer o aluno para o centro do processo educativo, procurando envolve-lo ativamente no processo de ensino-aprendizagem. Paralelamente, estas metodologias exigem do aluno uma responsabilidade adicional, a responsabilidade de gerir a sua própria aprendizagem (NOVEMBER, 2012). A seguir, apresenta-se cinco destas metodologias alternativas como forma de ilustrar possibilidades de sua utilização no ensino de ciências.

\section{Just-in-time Teaching - Ensino sob Medida}

O Ensino sob Medida, originalmente denominado de Just-in-Time Teaching, (NOVAK et al., 1999) move o elemento "transferência de conteúdo" do curso para a preparação pré-classe e concentra o tempo de aula na resolução colaborativa de problemas, encorajando as abordagens de aprendizagem ativas mais indicadas para promover a aprendizagem (NATIONAL RESEARCH COUNCIL, 2000).

Os alunos preparam-se para cada aula lendo o livro e fazendo um conjunto de tarefas (puzzles, WarmUps - exercícios de aquecimento...) postados na web. As respostas dos alunos são entregues ao professor algumas horas antes do início das aulas, permitindo antes do início da aula, saber os conhecimentos dos alunos e mapear as principais dificuldades. Assim, o tempo de aula pode-se concentrar nos pontos para os quais os alunos precisam de mais ajuda e podem ser estruturados em torno de respostas específicas dos alunos, permitindo um elemento de personalização.

Fortemente baseada na teoria de aprendizagem construtivista, o Ensino sob Medida incorpora o conhecimento pré-existente do aluno como essencial no processo de aprendizagem. Os equívocos pré-existentes podem servir de barreiras para o desenvolvimento de novos modelos mentais mais precisos. O Ensino sob Medida incorpora este elemento regularmente através do uso de WarmUps, o que pode ajudar a revelar equívocos e conhecimento prévio e ajudar a concentrar as atividades de classe nos elementos que mais precisam de discussão.

Esta metodologia é possível graças ao conceito de aulas invertidas (flipped classroom), uma vez que o aluno ao realizar o conjunto de tarefas propostas na web (antes da aula) está a preparar-se para a mesma, garantindo assim um tempo mais eficiente para a discussão na sala de aula. Durante a aula, o professor procura criar um ambiente interativo que enfatize a aprendizagem e a resolução colaborativa de problemas. 
A avaliação constante é um elemento-chave do Ensino sob Medida, ocorrendo durante essencialmente todas as reuniões de classe através de respostas do professor pelos WarmUps que o estudante envia em preparação para a aula.

Atualmente existe um corpo sólido de investigação que permite concluir que esta metodologia conseguiu alcançar resultados positivos na aprendizagem conceitual e no desenvolvimento de habilidades sociais e cognitivas, conseguindo modificar, com sucesso, a dinâmica das aulas (FORMICA; EASLEY; SPRAKER, 2010; ARAUJO; MAZUR, 2013).

\section{Peer Instruction - Instrução pelos Colegas}

A Instrução pelos Colegas é uma das metodologias ativas mais difundidas no mundo e foi proposta por Eric Mazur em meados da década de 90, na Universidade de Harvard (MAZUR; HILBORN, 1997). Em termos gerais, cada aula é introduzida com uma questão conceitual na forma de escolha múltipla. Os alunos têm um a dois minutos para pensarem individualmente sobre a questão e dão a sua resposta através de um sistema de aquisição de dados, clickers, ou flashcards (cartões de resposta). Se a frequência de acertos for superior a $70 \%$, o professor explica a resposta e faz novamente uma questão do mesmo tópico ou segue para o próximo conceito. Se a percentagem de acertos for inferior a 70\%, os alunos discutem com os colegas do lado e voltam novamente a votar (MAZUR; HILBORN, 1997; ARAUJO; MAZUR, 2013). A fase de discussão, geralmente com os alunos em pequenos grupos de 2 a 5 pessoas, dura normalmente 2 a 5 minutos. De certa maneira, a Instrução pelos Coelgas pressupõe aulas invertidas porque o aluno deve fazer um estudo prévio dos materiais antes de cada aula.

Os resultados ao longo destas duas décadas mostram que o aumento do índice de acerto após discussão com os colegas é bastante significativo, o que veio mostrar a importância da componente colaborativa na aprendizagem (CROUCH; MAZUR, 2001; LASRY; MAZUR; WATKINS, 2008; ARAUJO; MAZUR, 2013).

Em muitas escolas, os clickers foram já abandonados e substituídos por plataformas como o Socrative, Plickers ou Leraning Catalytics.

\section{Team-based learning - Aprendizagem Baseada em Times}

A Aprendizagem Baseada em Times tem algumas décadas e já foi adotada por várias dezenas de sistemas de ensino mundiais (MICHAELSEN; SWEET, PARMELEE, 2008). Em termos gerais baseia-se numa aprendizagem conseguida por times. Os autores esclarece os quatro elementos essenciais para a implementação 
desta metodologia: a) a formação de grupos deve ser criteriosamente escolhida; b) os alunos devem ser responsabilizados pela sua aprendizagem a pela aprendizagem dos membros dos seus grupos (por exemplo, se um aluno não se preparar para uma aula, vai ser prejudicado assim como toda a equipa); c) deve existir feedback imediato das tarefas/momentos de avaliação realizado(s) pelos alunos; e, d) as tarefas propostas a cada grupo devem promover a aprendizagem de um determinado tópico mas também promover o trabalho em equipe, de forma a que as tarefas não sejam divididas mas feitas sempre de forma colaborativos.

A auto e heteroavaliação por parte dos elementos da equipe é uma das premissas para o sucesso deste modelo colaborativo (MICHAELSEN; SWEET, PARMELEE, 2008). Esta avaliação deve ser em consideração não só com o desempenho acadêmico (conhecimento científico) de cada membro, como também o profissionalismo (envolvimento nas atividades/responsabilidade) e a ética (capacidade de ouvir os colegas/troca de conhecimento)

Um típico modelo desta metodologia é composto por três partes; uma preparação prévia (em casa) por parte do estudante (aproximando-se assim do modelo das aulas invertidas); um momento de testes formativos (a iniciar cada aula e seguida de feedback imediato); por fim um conjunto de tarefas a realizar em grupo.

Mais recentemente, uma variante desta metodologia foi desenvolvida e testada por Eric Mazur, em Harvard: Team \& Project-based Approach (T\&PBA). Neste modelo, o ambiente de aprendizagem consiste num conjunto de atividades diversificadas (atividades de predição, tutoriais, problemas conceituais, atividades experimentais, entre outras), totalmente colaborativas e segundo o modelo de aulas invertidas. Neste ambiente há momentos breves de discussão por parte do professor e não existe exame final, apesar dos alunos serem continuamente avaliados e receberem feedback constante.

Este modelo inclui ainda a realização de três projetos em equipe que ocupam uma parte substancial do curso. Paralelamente, o curso tem um sistema de anotações online (MILLER et al., 2016) onde os alunos têm acesso ao livro utiizado no curso e fazem anotações. Esta metodologia tem vindo a ganhar expressão em todo o mundo, tendo sido já adotada em vários países, inclusive em universidades de referência, e em diferentes áreas.

\section{Project-based learning - Aprendizagem Baseada em Projetos}

A Aprendizagem Baseada em Projetos (APB) baseia-se no trabalho colaborativo, na interdisciplinariedade e na capacidade de resolução de problemas abertos (BENDER, 2014; PASQUALETTO; VEIT; ARAUJO, 2017). Para além da apren- 
dizagem acadêmica, esta metodologia procura desenvolver competências relacionadas com a responsabilidade social, o uso de novas tecnologias e a aplicação do conhecimento em novos contextos. Baseado no ensino por investigação (Inquiry), provavelmente tem as suas raízes em John Dewey e a William Heard Kilpatrick (PASQUALETTO; VEIT; ARAUJO, 2017)

Nesta metodologia, os alunos ganham conhecimento e competências trabalhando por um longo período de tempo para investigar e responder a uma pergunta, problema ou desafio autêntico, envolvente e complexo. O projeto é, geralmente, contextualizado por um problema significativo a resolver e foca-se nas metas de aprendizagem dos alunos, incluindo conteúdo e competências como pensamento crítico/resolução de problemas, comunicação, colaboração e autogestão. Durante este processo, os alunos são obrigados a tomar algumas decisões sobre o projeto e continuamente recebem comentários para melhorar seus processos e produtos.

\section{Modelo das estações laboratoriais}

O modelo das estações laboratoriais enquadra-se no modelo Team-Based learning e destina-se preferencialmente a aulas experimentais de disciplinas científicas, apesar de poder ser adotado e adaptado a qualquer disciplina. Neste modelo, o laboratório (sala de aula) é geralmente organizado em quatro ou cinco mesas (de acordo com o número de grupos formados) e com estações laboratoriais diferentes (MOTA; LOPES DOS SANTOS, 2012, 2013a, 2013b).

Durante a aula, cada grupo percorre sucessivamente as estações laboratoriais, cumprindo diferentes atividades/tarefas práticas previstas. As tarefas são diversificadas, apesar de dizerem respeito à mesma unidade temática. Por exemplo, numa aula de mecânica, podemos ter uma estação com a exploração de uma simulação PhET, ${ }^{1}$ onde os alunos têm disponível um computador para explorarem a simulação e responderem às questões da ficha laboratorial. Em outra estação, os alunos podem medir velocidades (ou tempos em uma célula fotoelétrica) de um corpo em queda livre, para verificar experimentalmente que a aceleração gravitacional não depende da massa, nem da altura para quedas próximas da superfície terrestre. Em outra estação, podem ter um problema mais aberto: um bloco em repouso em um plano inclinado. $\mathrm{O}$ objetivo da tarefa é levar o aluno a encontrar o valor do coeficiente de atrito estático tendo apenas uma régua e uma balança à sua disposição.

Algumas das respostas solicitadas aos alunos podem ser escritas ou incluir a realização de simulações e/ou produção de elementos para apresentar oralmente ao professor, que deverá avaliar, imediatamente, o desempenho do(s) aluno(s) e/ou do grupo. As respostas dadas, algumas em tempo real, informam o professor das 
aprendizagens conseguidas e/ou a necessidade de serem revisitadas por parte dos alunos em aulas posteriores (MOTA; LOPES DOS SANTOS, 2012, 2013a, 2013b). A seguir, ilustra-se uma estação laboratorial para alunos do ensino fundamental, no domínio da ótica (espelhos planos).

A atividade está assim descrita para os alunos: Com o material disponível na tua bancada (um espelho "Reflect-view", uma cartolina e uma vela acesa) demonstre como se pode explicar que a imagem num espelho plano é virtual.

Uma imagem é virtual quando não há luz na região da imagem, ou seja, quando ela é formada pelo prolengamento dos raios luminosos. Assim, na parte de trás do espelho (onde a imagem se forma) não há difusão de luz proveniente (luz refletida/emitida pelo objeto). Para verificar isso, basta que o aluno coloque uma cartolina no local onde se forma a imagem e perceberá que a imagem permanece inalterada. A Figura 1 mostra uma ilustração desta estação.

Figura 1 - Fotografia de uma estação laboratorial com o espelho plano Reflect-View e uma vela acesa - a imagem é formada atrás do espelho e é virtual

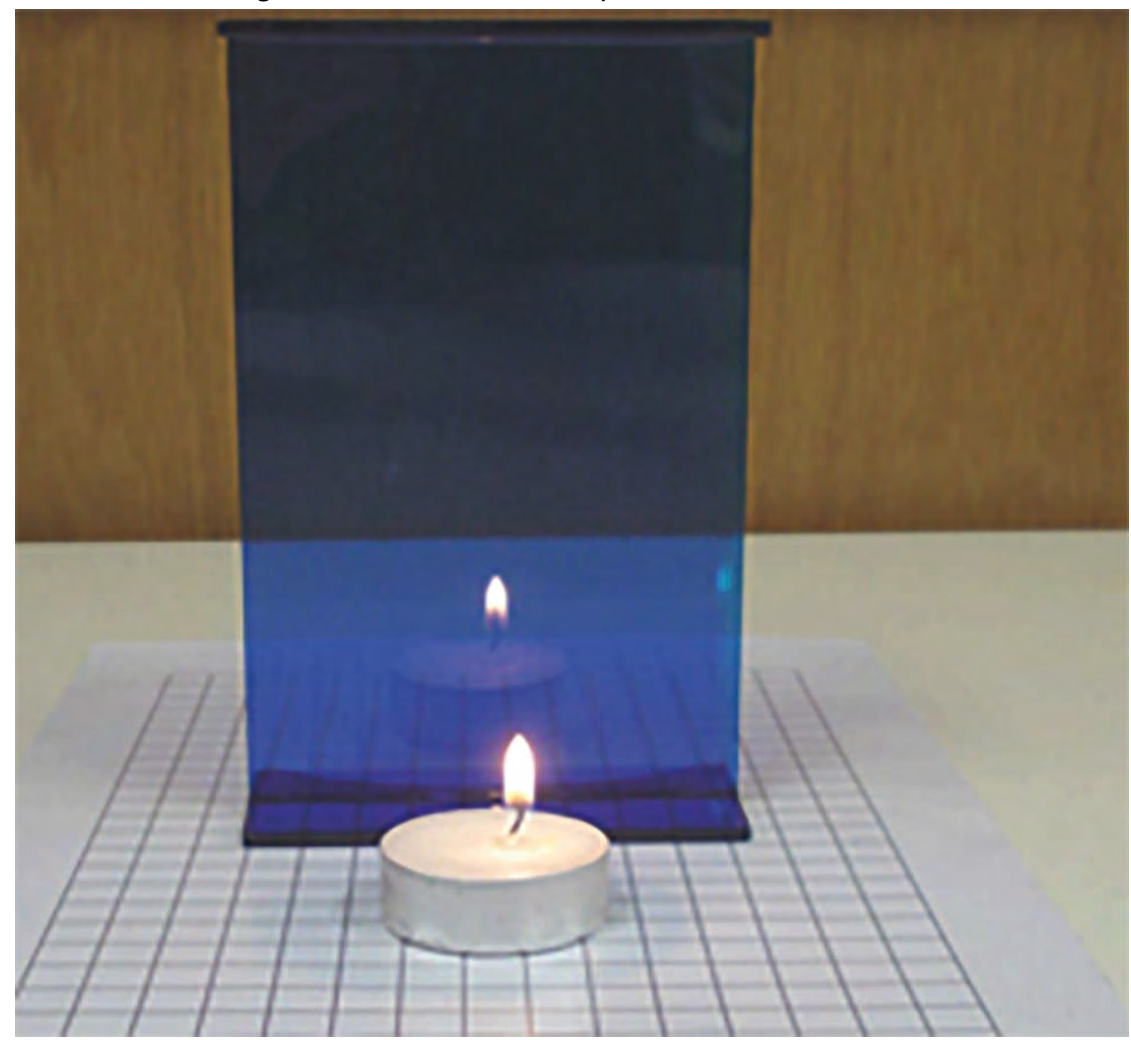

Fonte: arquivo pessoal, 2017. 
O professor depois de ouvir os alunos, avalia na própria ficha (Figura 2) o desempenho da tarefa e discute com os alunos eventuais dúvidas/erros.

Figura 2 - Excerto de uma ficha laboratorial onde o professor anota a avaliação

\section{Avaliação do professor:}

Demonstração: $\quad \square$ Correta $\quad \square$ Incompleta $\square$ Incorreta

Assinatura

Fonte: dados da pesquisa.

As atividades projetadas pelo professor podem ter diferentes graus de abertura, devem incluir as ideias pré-existentes erradas dos alunos (concepções alternativas) e, para ser possível a rotação simultânea dos grupos, todas as estações devem ser independentes e ter, aproximadamente, a mesma duração.

Contrariamente à clássicas aulas experimentais em que os alunos fazem simultaneamente a mesma atividade, o que exige repetição de material e limita a quantidade e qualidade de atividades ao longo do ano, neste modelo o professor precisa de menos material disponível. A função do professor é monitorar o trabalho de cada grupo, ajudando os alunos sempre que necessário e procurando que estes se tornem independentes. Ao supervisionar os alunos nas diversas atividades, o instrutor pode avaliar o modo como os alunos manipulam, interagem, discutem ideias, aplicam e constroem conhecimento.

\section{Trinta anos de metodologias ativas e o foço entre a pesquisa académica e a sala de aula}

O mundo académico luta há 30 anos para ultrapassar a fragmentação dos conteúdos e as técnicas de memorização dos conhecimentos presentes no ensino tradicional e conservador da escola, apostando no desenvolvimento das metodologias ativas. Infelizmente, este processo de implementação continua lento, pois muitos professores continuam presos a um ensino voltado à memorização e à exposição verbal. Os docentes evitam os ambientes experimentais; por um lado porque este tipo de ambientes requer um considerável investimento em termos de tempo (na preparação e implementação), por outro porque os docentes não conseguem reconhecer, em tempo útil, a aprendizagem dos alunos neste tipo de aulas. A estes 
fatores acresce a dificuldade sentida pelos professores em controlar e avaliar os alunos nestas aulas. Assim, este tipo de ambientes é desvalorizado pela classe docente que muitas vezes lhe atribui apenas um papel motivador.

As metodologias ativas anteriormente apresentadas e discutidas foram apresentadas individualmente mas o seu uso conjunto parece ser a melhor opção. Todas elas constituem-se como forma concreta de viabilizar ideias centrais da Teoria da Aprendizagem Significativa de Ausubel (AUSUBEL, 1963), da Teoria socioconstrutivista de Vigotski (VIGOTSKI, 1986) e do pensamento metacognitivo, aliado aos mais recentes indicadores da neurociência.

Cabe ao professor regatar a necessidade da educação ser estruturada neste grande pilar: um ensino que não vise apenas a aprendizagem dos conteúdos específicos das disciplinas, mas que também apresente a intenção de ensinar o estudante a aprender a aprender, assegurando-lhe a busca pelo conhecimento em condições diferentes das apresentadas pelo professor, inclusive fora dos muros escolares.

\section{Notas}

1 Disponível em: <https://phet.colorado.edu/pt/simulations>. Acesso em: 10 out. 2017.

\section{Referências}

ARAUJO, Ives S.; MAZUR, Eric. Instrução pelos colegas e ensino sob medida: uma proposta para o engajamento dos alunos no processo de ensino-aprendizagem de Física. Caderno Brasileiro de Ensino de Física, Florianópolis, v. 30, n. 2, p. 364-384, 2013.

ARONS, Arnould B. Teaching introductory physics. New York: John Wiley \& Sons, 1997.

AUSUBEL, David P. The psychology of meaningful verbal learning. Oxford: Grune \& Stratton, 1963.

BENDER, William N. Aprendizagem baseada em projetos: educação diferenciada para o século XXI. Porto Alegre: Penso, 2014.

CHI, Michelene T. H.; ROSCOE, Rod D. The process and challenges of conceptual change. In: LIMÓN, Margarita; MASON, Lucia (Ed.). Reconsidering conceptual change: issues in theory and practice. New York: Kluwer Publishers, 2002. p. 3-27.

CROUCH, Catherine H.; MAZUR, Eric. Peer instruction: ten years of experience and results. American Journal of Physics, Maryland, v. 69, n. 6, p. 970-977, 2001.

DESLAURIERS, Louis; SCHELEW, Ellen; WIEMAN, Carl. Improved learning in a large-enrollment physics class. Science, Washington, v. 332, n. 6031, p. 862-864, 2011.

DOCKTOR, Jennifer L.; MESTRE, José P. Synthesis of discipline-based education research in physics. Physical Review Physics Education Research, Washington, v. 10, n. 2, p. 020119-1-58, 2014. 
FLAVELL, John H. Metacognitive aspects of problem solving. In: RESNICK, Lauren B. (Ed.). The nature of intelligence. Hillsdale, NJ: Lawrence Erlbaum Associates, 1976. p. 231-236.

FLAVELL, John H. Metacognition and cognitive monitoring: a new area of cognitive - development inquiry. American Psychologist, Washington, v. 34, n. 10, p. 906-911, 1979.

FISHER, Robert. Thinking about thinking: developing metacognition in children. Early Child Development and Care, Abingdon, v. 141, n. 1, p. 1-15, 1998.

FORMICA, Sarah P.; EASLEY, Jessica L.; SPRAKER, Mark C. Transforming common-sense beliefs into Newtonian thinking through Just-In-Time Teaching. Physical Review Physics Education Research, Washington, v. 6, n. 2, p. 020106-1-020106-17, 2010.

GEORGHIADES, Petros. From the general to the situated: three decades of metacognition. International Journal of Science Education, Abingdon, v. 26, n. 3, p. 365-383, 2004.

HAKE, Richard R. Interactive-engagement versus traditional methods: A six-thousand-student survey of mechanics test data for introductory physics courses. American Journal of Physics, Maryland, v. 66, p. 64-74, 1998.

KNIGHT, Randall. Five easy lessons: strategies for successful physics teaching. São Francisco: Addison Wesley, 2004.

LASRY, Nathaniel; MAZUR, Eric; WATKINS, J. Peer Instruction: from Harvard to the two-year college. American Journal of Physics, Maryland, v. 76, p. 1066-1069, 2008.

MAZUR, Eric; HILBORN, Robert C. Peer Instruction: a user's manual. Physics Today, Maryland, v. 50, n. 4, p. 65, 1997.

MCDERMOTT, Lillian C. Guest comment: How we teach and how students learn - a mismatch? American Journal of Physics, Maryland, v. 61, p. 295-298, 1993.

MCDERMOTT, Lillian C. Physics by Inquiry. New York: John Wiley \& Sons, 1996.

MCDERMOTT, Lillian C.; SHAFFER, Peter S. J. Tutorials in Introductory Physics. New Jersey: Pearson Education, 2001.

MICHAELSEN, Larry K.; SWEET, Michael; PARMELEE, Dean X. Team-Based Learning: small group learning's next big step. New York: Wiley Periodicals, 2008.

MILLER, Kelly et al. Role of physics lecture demonstrations in conceptual learning. Physical Review Physics Education Research, Washington, v. 9, p. 020113-1-020113-5, 2013.

MILLER, Kelly et al. Analysis of student engagement in an online annotation system in the context of a flipped introductory physics class. Physical Review Physics Education Research, Washington, v. 12, p. 020143-1-020143-12, 2016.

MOREIRA, Marco Antonio. Ensino de Física no Brasil: Retrospectiva e Perspectivas. Revista Brasileira de Ensino de Física, São Paulo, v. 22, n. 1, p. 94-99, 2000.

MOTA, Ana Rita; LOPES DOS SANTOS, João. Eratosthenes' measurement of the Earth's radius in a middle school lab session. Latin-American Journal of Physics Education, Washington, v. 6, Suppl. I, p. 139-144, 2012. 
MOTA, Ana Rita; LOPES, José Manuel; LOPES DOS SANTOS, João. Estações laboratoriais: uma aposta no ensino experimental. Gazeta da Física, Lisboa, v. 36, n. 1, p. 25-28, 2013a.

MOTA, Ana Rita; LOPES DOS SANTOS, João. Reflecting understanding: using lab stations to teach image formation. Science Scope, v. 37, n. 2, p. 20-29, 2013b.

NATIONAL RESEARCH COUNCIL. How people learn: brain, mind, experience and school. BRANSFORD, John D.; BROWN, Ann L.; COCKING, Rodney R. (Ed.). Washington: National Academy Press, 2000.

NOVAK, Gregor et al. Just-In-Time Teaching: Blending Active Learning with Web Technology. New Jersey: Prentice Hall, 1999.

NOVEMBER, Alan. Who owns the learning? Preparing students for success in the digital age. New York: Solution Tree, 2012.

PARIS, Scott G.; WASIK, Barbara A.; TURNER, Julianne C. The development of strategic readers. In: BARR, Rebecca et al. (Org.). Handbook of reading research. Hillsdale, NJ: Lawrence Erlbaum Associates, 1991. v. 2. p. 609-640.

PASQUALETTO, Terrimar; VEIT, Eliane Angela; ARAUJO, Ives Solano. Aprendizagem baseada em projetos no ensino de Física: uma revisão da literatura. Revista Brasileira de Pesquisa em Educação em Ciências, Belo Horizonte, v. 17, n. 2, p. 551-577, 2017.

PINTRICH, Paul R. The Role of Metacognitive Knowledge in Learning, teaching and Assessing. Theory Into Practice, Abingdon, v. 41, n. 4, p. 219-225, 2002.

ROSA, Cleci T. Werner da. Metacognição no ensino de Física: da concepção à aplicação. Passo Fundo: UPF Editora, 2014.

SLAVIN, Robert. Students motivating students to excel: cooperative incentives, cooperative tasks, and student achievement. The Elementary School Journal, Chicago, v. 85, n. 1, p. 53-63, 1984.

THACKER, Beth; KIM, Eunsook; TREFZ, Kelvin. Comparing problem solving performance of physics students in inquiry based and traditional introductory physics courses. American Journal of Physics, Maryland, v. 62, n. 7, p. 627-633, 1994.

VIENNOT, Laurence. Teaching Physics. Boston: Kluwer Academic Publishers, 2003.

VIGOTSKI, Lev Semenovich. Thought and Language. Cambridge: The MIT Press, 1986.

VOSNIADOU, Stella. On the nature of naive physics In: LIMÓN, Margarita; MASON, Lucia (Ed.). Reconsidering conceptual change: issues in theory and practice. New York: Kluwer Publishers, 2002. p. 61-76. 